\title{
Variáveis Discriminantes do Nível de Institucionalização do Modelo Orçamentário nas UNIVERSIDADES FederaIS
}

\author{
Discriminant Variables of Institutionalization Level of the \\ Budget Model in Federal Universities
}

Cisne Zélia Teixeira Reis

Economista da Universidade Federal de Viçosa/Pró-Reitoria de Planejamento e Orçamento. Viçosa, MG. Brasil. E-mail: zelia@ufv.br

Adriel Rodrigues de Oliveira

Professor Associado da Universidade Federal de Viçosa/Departamento de Administração e Contabilidade. Viçosa, MG. Brasil. E-mail: aroli@ufv.br

Suely de Fátima Ramos Silveira

Professora Associada. Diretora do Instituto de Políticas Públicas e Desenvolvimento Sustentável. Universidade Federal de Viçosa/

Departamento de Administração e Contabilidade. Viçosa, MG. Brasil. E-mail: sramos@ufv.br

Nina Rosa da Silveira Cunha

Professora Associado da Universidade Federal de Viçosa/Departamento de Administração e Contabilidade. Viçosa, MG. Brasil. E-mail: ninarosa@ufv.br

\section{Resumo}

O rateio orçamentário entre as universidades federais é baseado num modelo matemático que considera a produção e o desempenho acadêmico de cada instituição, sendo fundamental que os gestores universitários conheçam, acompanhem e se estruturem a favor do melhor resultado nas variáveis que compõem o modelo. Por meio da Teoria Institucional, buscouse identificar e analisar o nível de institucionalização do modelo orçamentário $e$ as variáveis que mais diferenciam as universidades. Os resultados indicam que essas variáveis estão relacionadas à capacidade de aceitar a influência dos stakeholders; de compartilhar ideias e práticas; e de adotar ações estratégicas compatíveis com os princípios do modelo orçamentário.

Palavras-chave: Teoria Institucional. Modelo Orçamentário. Universidades Federais. Gestão Pública Universitária.

\section{Abstract}

The budg lotment among the federal universities is based on a mathematical model that considers the production and academic performance of each institution, and it is essential that the university managers know, follow and are structured in favor of better results in the variables that make up for the model. Through the Institutional Theory, we tried to identify and analyze the institutionalization level of the budget model and the variables that most distinguished the universities. The results indicate that these variables are related to the ability to accept the influence of stakeholders, to share ideas and practices and to adopt strategic actions according to the principles of the budget model.

Keywords: Institutional Theory. Budget Model. Federal Universities. University Public Administration. 


\section{INTRODUÇÃO}

Desde 1994 o Ministério da Educação e Cultura (MEC) adota um modelo matemático para alocação dos recursos orçamentários entre as universidades federais, com os objetivos de assegurar a estabilidade do financiamento das universidades, garantir o equilíbrio da alocação orçamentária entre as universidades e efetuar a alocação a partir de critérios previamente definidos e divulgados.

O modelo busca alocar os recursos orçamentários em função da produção acadêmica e do desempenho das universidades em variáveis e indicadores que mais guardam relação com a necessidade de recursos para a manutenção e desenvolvimento de suas atividades.

Além disso, o modelo visa contemplar as metas governamentais para expansão e melhoria da educação superior pública, estabelecidas no Plano Nacional de Educação (PNE), entre elas: duplicar o número de alunos nas salas de aula das universidades públicas federais, atingir a meta de 18 alunos/professor, aumentar a taxa de conclusão de cursos de graduação (chegar a $90 \%$ ), ampliar a oferta do ensino noturno, democratizar o acesso à graduação e propiciar a interiorização da universidade, com a criação de campi.

Cumprir as metas governamentais para a educação superior, melhorando seus indicadores, torna-se fundamental tanto para o processo de avaliação das universidades, como também para a definição de seu financiamento.

Com isso, é primordial que a universidade, respeitada sua missão, planeje e avalie a implementação de ações que reflitam positivamente no seu posicionamento no modelo orçamentário. É importante que os gestores universitários conheçam, acompanhem $e$ se estruturem em favor do melhor desempenho nas variáveis e indicadores do modelo.

Entendendo ser o modelo orçamentário uma ferramenta de gestão revestida dos princípios da administração pública gerencial, uma vez que está focada no alcance de resultados e prestação de serviços públicos de qualidade, faz-se necessário investigar o empenho da universidade em aprimorar suas capacidades gerenciais em favor da incorporação efetiva do modelo orçamentário em seus hábitos e rotinas.

Para tanto, buscou-se na Teoria Institucional o suporte teórico necessário, segundo a qual, uma norma, ação ou arranjo organizacional está institucionalizado quando faz parte dos hábitos e rotinas da organização.

Esta pesquisa tem por objetivo agrupar as Universidades Federais conforme o estágio de institucionalização em que se encontram em relação ao modelo de alocação de recursos orçamentários, identificando as variáveis que mais discriminam os grupos formados.

\section{Modelo de Alocação de Recursos OrÇamentários das Universidades FEDERAIS}

No intuito de alterar o cenário até então vigente, em que critérios históricos ou interferências de ordem política determinavam o orçamento das universidades federais brasileiras, em 1991, o MEC e a Associação Nacional dos Dirigentes das Instituições Federais de Ensino Superior (ANDIFES) iniciaram as discussões para elaboração de metodologias, aderindo, assim, ao modelo de financiamento por fórmulas. Dessa forma, poder-se-ia assegurar a estabilidade do financiamento das universidades, garantir o equilíbrio da alocação orçamentária entre as universidades e efetuar a alocação de recursos a partir de critérios previamente definidos e divulgados.

Materializado no que se convencionou chamar de "Matriz Andifes", o modelo é resultado de esforços evolutivos e conjuntos para dotação de metodologia de rateio de recursos orçamentários para a manutenção destas instituições numa parceria e diálogo entre a ANDIFES e a Secretaria de Educação Superior do Ministério da Educação (Sesu/MEC).

O modelo visa alocar recursos orçamentários para realização das despesas de custeio e investimento das universidades, denominado Outros Custeios e Capital (OCC), e refere-se, basicamente, ao orçamento total da universidade subtraído os recursos destinados a despesas relacionadas com pessoal. Os recursos orçamentários de OCC se destinam à realização das despesas correntes relacionadas à aquisição de Material de Consumo, Diárias, Passagens, Locação de mão de obra, Serviços de Pessoa Física, Serviços de Pessoa Jurídica e outras, bem como das despesas de capital, como Obras, Equipamentos e Material Permanente.

Fruto das negociações iniciadas no ano de 1991, em 1994, a Portaria Ministerial n. 1.285/1994/MEC (a 
Portaria Ministerial n. 1.285/MEC, de 5 de agosto de 1994, foi publicada no DOU de 6-9-1994), instituiu, pela primeira vez, um modelo matemático para alocação de recursos orçamentários entre as instituições federais de ensino superior.

Este primeiro modelo era um modelo de partição, pois sua aplicação gerava um valor de percentuais de distribuição dos recursos de OCC a incidir sobre o montante dos recursos do MEC disponíveis para a manutenção das universidades. Era constituído de três componentes: o Histórico, o Input e o Output, em que o componente histórico compunha $90 \%$ do rateio e apenas os outros $10 \%$ em função do desempenho da universidade em variáveis relacionadas ao tamanho e qualidade da universidade.

Tendo vigorado no período de 1994 a 1998, a metodologia instituída pela referida Portaria sofreu alterações, passando, em 1999 a ser composta de duas submatrizes: Matriz de Ensino e Matriz de Pesquisa. A Matriz de Ensino considerava variáveis como alunos matriculados, concluintes, ingressantes, vagas no vestibular, peso do curso (em função de seu custo), bônus para fora de sede, bônus para cursos noturnos, taxa de retenção e taxa de evasão. Por meio de fórmulas específicas, calculava-se o Número Equivalente de Estudantes em Tempo Integral. Já a Matriz de Pesquisa considerava o número de docentes envolvidos com a pós-graduação e a avaliação da Capes dos programas de mestrado e doutorado.

Numa combinação dos percentuais resultantes da Matriz de Ensino e da Matriz de Pesquisa, ocorria uma partição do montante orçamentário, o que provocava competição entre as universidades, num cenário em que "[...] o bolo financeiro é praticamente o mesmo de um ano para o outro, e quando uma instituição conseguia aumentar a sua fatia é porque outras instituições, obrigatoriamente, ficaram com porções menores". (AMARAL, 2003, p. 116)

Assim, a partir de 2005, nova metodologia foi implementada e se encontra em vigor, desenvolvida de modo que possa incorporar importantes aspectos da gestão universitária, como: reconhecimento da heterogeneidade do Sistema IFES; estabelecimento de parâmetros indutores do desempenho que induzam a diminuição da evasão e da retenção; estabelecimento de parâmetros indutores de superação de desigualdades e que incentivem a criação de cursos noturnos e de licenciaturas; e valorização da interiorização da universidade.

A atual metodologia de distribuição de recursos orçamentários de OCC entre as universidades passa a ter dois componentes: o Orçamento Básico e o Orçamento de Investimento (BRASIL, 2006) e busca utilizar indicadores que possam ser facilmente auditados $e$ induzir o aumento da qualidade dos serviços prestados pelas universidades.

O Orçamento Básico é constituído de duas parcelas. A primeira, denominada Parcela de Manutenção utiliza um modelo sem partição considerando a Unidade Básica de Custeio (UBC) multiplicado pelo Número de Alunos Equivalentes da cada IFES, o que corresponde a $80 \%$ do valor total do Orçamento de Manutenção. A segunda parcela, denominada Parcela de Qualidade e Produtividade (IQP), utiliza um modelo de partição para definir os $20 \%$ que completam o orçamento total, considera indicadores como o próprio nome sugere por se considerar importante que o modelo contemple aspectos qualitativos, mantendo, portanto, uma componente competitiva. (BRASIL, 2006)

A UBC é utilizada no modelo como um dos parâmetros para identificar a necessidade do custeio das instituições, compostas de itens de despesas que foram considerados de maior impacto orçamentário, como: energia elétrica, água e esgoto, telecomunicações, correios, vigilância, limpeza, diárias, passagens, combustíveis, etc.

O Número de Aluno-Equivalente (NAE), principal indicador utilizado no modelo orçamentário das universidades, compõe o Vetor Ensino e é calculado para a graduação, mestrado, doutorado e residência médica conforme fórmulas (1), (2), (3) e (4), respectivamente:

$N A E_{(G)}=\left\{\left[N_{d i} \times D \times(1+R)\right]+\left[\left(\frac{N_{i}-N_{d i}}{4}\right) \times D\right]\right\} \times B T \times B F S \times P G$

Em que:

\begin{tabular}{c|c|c}
$\mathrm{NAE}_{(\mathrm{G})}$ & $=$ & $\begin{array}{c}\text { Número de alunos equivalentes } \\
\text { (graduação) }\end{array}$ \\
\hline $\mathrm{N}_{\mathrm{di}}$ & $=$ & Número de diplomados \\
\hline $\mathrm{D}$ & $=$ & Duração-padrão do curso \\
\hline $\mathrm{R}$ & $=$ & Coeficiente de retenção \\
\hline $\mathrm{N}_{\mathrm{i}}$ & $=$ & Número de ingressantes \\
\hline $\mathrm{BT}$ & $=$ & Bônus por turno noturno \\
\hline
\end{tabular}




\begin{tabular}{c|c|c}
\hline BFS & $=$ & Bônus por curso fora de sede \\
\hline PG & $=$ & Peso do Grupo \\
$N A E_{(M)}=N M \times f M D \times P G$
\end{tabular}

Em que:

\begin{tabular}{c|c|c}
$\mathrm{NAE}_{(\mathrm{M})}$ & $=$ & $\begin{array}{c}\text { Número de alunos equivalentes } \\
\text { (mestrado) }\end{array}$ \\
\hline $\mathrm{NM}$ & $=$ & $\begin{array}{c}\text { Número de alunos matriculados } \\
\text { efetivos do mestrado }\end{array}$ \\
\hline Fmd & $=$ & $\begin{array}{c}\text { Fator de tempo dedicado a cursar } \\
\text { disciplinas }(0,75)\end{array}$ \\
\hline PG & $=$ & Peso do Grupo
\end{tabular}

$\mathrm{V}_{A} E_{(D)}=N D \times f D D \times P G$

\begin{tabular}{c|c|c}
\multicolumn{2}{c}{ Onde, } \\
$\mathrm{NAE}_{(\mathrm{D})}$ & $=$ & $\begin{array}{c}\text { Número de alunos equivalentes } \\
\text { (doutorado) }\end{array}$ \\
\hline $\mathrm{ND}$ & $=$ & $\begin{array}{c}\text { Número de alunos matriculados } \\
\text { efetivos do doutorado }\end{array}$ \\
\hline $\mathrm{fDD}$ & $=$ & $\begin{array}{c}\text { Fator de tempo dedicado a cursar } \\
\text { disciplinas }(0,38)\end{array}$ \\
\hline PG & $=$ & Peso do Grupo
\end{tabular}

$$
N A E_{(R)}=N M R M
$$

Onde,

\begin{tabular}{c|c|c}
$\mathrm{NAE}_{(\mathrm{R})}$ & $=$ & $\begin{array}{c}\text { Número de alunos equivalentes } \\
\text { (residência) }\end{array}$ \\
\hline NMRM & $=$ & $\begin{array}{c}\text { Número de alunos matriculados nos } \\
\text { Programas de Residência Médica }\end{array}$
\end{tabular}

Para o cálculo final do aluno equivalente, os alunos equivalentes dos diversos níveis de escolaridade, graduação, mestrado, doutorado e residência médica, são apenas somados.

O Número de Aluno-Equivalente da Graduação pressupóe que o aluno matriculado em cada curso neste nível de ensino possa se equivaler a um número maior em função do número de ingressantes e do número de concluintes, respeitadas as condições médias pré-estabelecidas de retenção, duração padrão e peso do grupo a que o curso pertença conforme de seu cus- to. Desta forma, a universidade tende a ter um maior valor de Aluno-Equivalente de Graduação quando o número de ingressantes e o número de concluintes são, no mínimo, iguais ao número de vagas do curso.

O outro indicador para definição do orçamento da universidade é o Índice de Qualidade e Produtividade (IQP), que vai compor o Vetor Pós-Graduação e Pesquisa (PGP) na Matriz orçamentária. O PGP corresponde à ponderação das variáveis: número de cursos de mestrado, doutorado e residência médica em $10 \%$; número de dissertações, teses e residência em $13 \%$; e número de pontos total do conceito Capes em $4 \%$. O índice resultante desses $27 \%$ é convertido em $100 \%$ para definição do valor relativo de PGP de cada universidade na matriz. O Índice de Qualidade e Produtividade (IQP), então, é o resultado de $50 \%$ do índice do NAE de cada universidade e de cinquenta por cento do índice do PGP.

Quanto ao Orçamento de Investimento, é constituído da Parcela de Equalização e da Parcela de Políticas Públicas e Expansão do Sistema Federal de Ensino Superior, e os recursos são alocados mediante apresentação de projetos com vistas à conservação da infraestrutura física e patrimonial e expansão do sistema público de educação superior. (BRASIL, 2006)

Anualmente a matriz de alocação de recursos orçamentários é submetida à atualização e pequenas adaptações e, ou alterações com vistas à melhoria do modelo.

O Decreto n. 7.233 (BRASIL, 2010), em seu artigo $4^{\circ}$, estabelece que a matriz de distribuição de recursos orçamentários das universidades federais considere, além dos atuais, outros parâmetros, como: a produção do conhecimento científico, tecnológico, cultural e artístico, o número de registro e comercialização de patentes; a relação alunos/docentes na graduação e na pós-graduação; os resultados da avaliação pelo Sistema Nacional de Avaliação da Educação Superior (SINAES); e programas institucionalizados de extensão, com indicadores de monitoramento. O Decreto sinaliza a importância dada ao estabelecimento de critérios para alocação de recursos orçamentários entre as universidades federais e a necessidade de inserir no atual modelo outras variáveis relacionadas à eficiência, produção acadêmica e qualidade do ensino. 


\section{Referencial Teórico}

Esta pesquisa buscou na Teoria Institucional o suporte teórico necessário à análise e compreensão do comportamento das universidades federais em relação à institucionalização de seu Modelo de Alocação de Recursos Orçamentários de Outros Custeios e Capital.

Inicialmente, recorreu-se aos princípios definidos para a administração pública gerencial, por se entender que o modelo orçamentário das universidades federais enquadra-se neles como um dos instrumentos, dos quais a gestão pública universitária pode lançar mão para propiciar a prestação de serviços com eficiência e transparência, pautada no alcance de resultados.

\subsection{A Gestão Universitária sob a Perspectiva da Administração Pública Gerencial}

Para que o Estado possa cumprir suas funções e prestar à sociedade serviços públicos de qualidade, é necessário que ele esteja estruturado e preparado para o exercício de uma administração pública mais ágil e flexível a fim de responder aos novos desafios impostos, principalmente pela redução de receitas públicas e a maior cobrança de resultados pela sociedade.

No Brasil, o movimento em prol da adoção de modelo de administração pública gerencial teve início nos anos 1990 e resultou no documento chamado "Plano Diretor da Reforma do Aparelho Estatal" (PDRAE) de 1995. Nesse documento foram estabelecidas as condições para a melhoria da gestão pública, como: preocupação com a eficiência da ação governamental; orientação para obtenção de resultados; foco no atendimento às necessidades dos cidadãos-usuários; controle voltado para os resultados; fortalecimento do controle social; e transparência e gestão responsável. (BRESSER-PEREIRA, 2006)

Abrucio (2007), ao fazer um balanço da reforma da administração pública, comenta que, ainda que não tenham sido feitas todas as mudanças institucionais idealizadas, ela proporcionou um "choque cultural", exercendo influência na atuação de gestores públicos e numa série de inovações governamentais nos últimos anos.

Em recente trabalho, Bresser-Pereira (2011, p. 3), manifestou que a Reforma Gerencial de 1995 “[...] foi - e continua a ser, já que está em pleno processo de implementação - uma resposta aos desafios apresentados pela transformação do Estado brasileiro em um Estado social, depois da transição democrática de 1985".

As universidades federais, como organizações públicas, devem buscar desempenhar sua missão sob a ótica da administração gerencial, de modo que

[...] atue no eixo da fixação de metas, da avaliação de desempenho, do uso de incentivos, com o fim de aumentar a eficácia $e$ a equidade do sistema, reforçar a autonomia $e$ a iniciativa dos centros educacionais, desta maneira, caracteriza também o novo tipo de relação que deverá estabelecer-se entre o sistema educacional, o Estado $e$ a sociedade civil [...]. (CEPAL, 1995, p. 206)

Na visão de Prates (2001), a gestão de organizações educacionais, sobretudo as universitárias, tem que levar em conta o enorme volume de incertezas consequência da impossibilidade de definir, de forma unívoca, os "produtos" da universidade - embutido nas atividades dos membros do corpo acadêmico, ou seja, nas atividades-fim da organização. Essa característica organizacional, entretanto, requer uma estrutura administrativa das atividades acadêmicas, muito mais sofisticada do que a burocrática.

Previsto na Constituição Federal, o Plano Nacional de Educação (PNE), de duração decenal, tem por objetivo articular o sistema nacional de educação em regime de colaboração e definir diretrizes, objetivos, metas e estratégias de implementação para assegurar a manutenção e desenvolvimento do ensino em seus diversos níveis, etapas e modalidades.

Especificamente, em relação à educação superior, o PNE (BRASIL, 2001) propõe como metas para o decênio 2001-2010 duplicar o número de alunos nas salas de aula das universidades públicas federais (Conforme PNE, Lei n. 10.172/2001, na América Latina, o Brasil possuía um dos índices mais baixos de porcentagem de matriculados na educação superior (menos de 12\%) dentro da população de 18 a 24 anos, ao passo que na Argentina este índice atingiu 40\%, no Chile, 20,6\%, na Venezuela, 26\%, e na Bolívia, 20,6\%), atingir a meta de 18 alunos/professor (Conforme PNE (BRASIL, 2001), essa relação é de 10 alunos por professor), aumentar a taxa de conclusão de cursos de graduação (chegar 
a 90\%), além de ampliar a oferta do ensino noturno, democratizar o acesso à graduação e propiciar a interiorização da universidade. Esse cenário é ratificado no Projeto de Lei do PNE para o decênio 2011-2020.

O uso de indicadores na gestão pública tem se tornado, nos últimos 20 anos, motivo de crescente interesse. De um lado, é possível observar a mídia, os sindicatos e a sociedade civil exercendo o poder de fiscalização do gasto público e exigindo uso eficiente, eficaz e efetivo dele (JANNUZZI, 2005); de outro, encontram-se as mudanças institucionais pelas quais vem passando a administração pública, em que se observa a consolidação da sistemática do planejamento plurianual, o aprimoramento dos controles administrativos dos ministérios, a mudança da ênfase da auditoria para a avaliação do desempenho dos programas e a reforma gerencial da gestão pública em meados dos anos 1990. (LUSTOSA DA COSTA; CASTANHAR, 2003)

Neste contexto, o orçamento público representa um instrumento em favor da eficiência gerencial do governo, na medida em que busca contemplar o planejamento das ações governamentais, a serem executadas com as receitas passíveis de serem arrecadadas num determinado exercício e sua destinação, pelas ações explicitadas nos diversos projetos e atividades, nas três esferas do poder público.

No âmbito do New Public Management, o orçamento por resultados ou desempenho é considerado uma estratégia operacional cujo objetivo é permitir a alocação de recursos com base em metas e objetivos de programas, em indicadores ou medidas de eficiência e efetividade, dentro de um sistema de accountability dos gestores que premie os bons resultados e puna os resultados ruins. (CAVALCANTE, 2009)

A principal fonte de financiamento das universidades federais é proveniente do Tesouro, podendo, ainda, contar com recursos próprios e convênios com órgãos públicos e privados. O financiamento, assim como a avaliação, nas palavras de Amaral (2005), fortemente acoplados como medida eficiente para alcançar as metas estabelecidas para o setor educacional, está vinculado a um modelo para a distribuição de recursos entre as IFES baseado, principalmente, no financiamento por fórmulas, conforme item 2 deste estudo.

Vale destacar o papel do gestor universitário no exercício de uma administração gerencial, para a qual deve, conforme apontado por Meyer Jr. (2000), apresentar importantes características, como: visão de futuro, domínio da tecnologia, visão estratégica, capacidade de decisão, prática de empowerment, gerenciamento de informações e ato de empreender e participar.

\subsection{Teoria Institucional}

Sob a perspectiva da abordagem institucional, o ambiente se constitui uma extensão do cotidiano organizacional, ou seja, entende-se que "[...] as organizações estão imersas em ambientes dos quais elas retiram e a eles transmitem modos adequados de ação, sobretudo de natureza estratégica". (FONSECA; MACHADO-DA-SILVA, 2010, p. 17)

Contudo, nessa perspectiva, o ambiente não é concebido apenas pela formação por recursos humanos, materiais e econômicos, mas também, segundo Carvalho et al. (1999), para destacar a presença de elementos culturais como valores, símbolos, mitos e crenças.

De acordo com Tolbert e Zucker (2006), antes do trabalho de Merton e seus discípulos, no final da década de 1940, as organizações não eram propriamente reconhecidas pelos sociólogos americanos como um fenômeno social distinto e merecedor de estudo próprio.

A concepção tradicional da Teoria Institucional, chamada velho institucionalismo, começa então a admitir a organização como expressão de valores sociais, destacando sua relação com o ambiente, apoiando o desenvolvimento das pesquisas de autores como Meyer, Meyer e Rowan, Meyer e Scott e Zucker, cujos resultados semearam os componentes centrais do pensamento neoinstitucionalista. (FONSECA, 2003)

Embora relacionado com a tradição sociológica de Selznick, o novo institucionalismo difere do velho ao adotar a influência do construtivismo social. Os neoinstitucionalistas, conforme Fonseca (2003), compartilham uma visão da realidade como socialmente construída.

Dimaggio e Powell (2005) salientam que o novo institucionalismo compreende uma rejeição à concepção racionalista e um retorno às explicações cognitivas e culturais. Suddaby (2010) alega que para que os sistemas de significado institucional sejam compreendidos e interpretados dentro das organizações, deve-se adotar uma perspectiva interna. 
O fenômeno da construção social, de acordo com Berger e Luckmann (1985), ocorre quando se observa a interação dos indivíduos no sentido de tornar habituais as ações, com vistas a possibilitar a divisão de trabalho e as inovações para formação de novos hábitos. Para Nor-Aziah e Scapens (2007), trata-se de um processo no qual a confiança, o poder e a resistência estão entrelaçados.

Para Meyer e Rowan (1977), os arranjos institucionais, como políticas formais de contratação, técnicas contábeis, orçamento e cargos ou funções associadas à equidade no emprego, adquiriram grande significado social nas organizações, sinalizando então para o comprometimento com padrões eficientes e racionais. No entanto, a adoção dos arranjos institucionais não garante legitimação; é necessário que seja percebida pelos stakeholders como instrumentos capazes de proporcionar uma gestão responsável.

Nesse sentido, Guerreiro et al. (2004, p. 4) asseveram que:

[...] o sistema de contabilidade gerencial pode ser visto como uma importante rotina no âmbito das organizações ou, ainda, a contabilidade gerencial pode ser enfocada como um conjunto fortemente estruturado de rotinas. Os orçamentos são elaborados, a performance monitorada e relatórios produzidos de um modo regular e rotineiro através de regras e procedimentos claramente especificado.

O orçamento é uma tradicional técnica de controle e pode, de acordo com Soutes (2006), ser considerado um artefato da Contabilidade Gerencial, pois se enquadra no conjunto de atividades, ferramentas, instrumentos e modelos de gestão utilizados pelos profissionais.

Assim, a utilização de um modelo de alocação de recursos orçamentários para as Universidades Federais pode caracterizar o esforço da administração pública em institucionalizar uma ferramenta que possa promover maior controle e eficiência na gestão de recursos públicos e na gestão universitária sob a forma de um arranjo institucional.

Zucker (1991), com base nos trabalhos de Berger e Luckmann, realizou um estudo com o propósito de investigar o efeito de diferentes níveis de institucionalização em realidades construídas sobre persistência cultural. Numa abordagem etnometodológica, o processo de institucionalização ocorreria em três etapas: transmissão de cultura (socialmente construída), manutenção da cultura e resistência às mudanças.

\subsubsection{Processos da Institucionalização}

Tolbert e Zucker (2006) retomam o estudo de Zucker e fazem uma análise do processo de institucionalização $e$ as forças causais que são críticas em seus diferentes pontos, conforme Figura 1, extensivo aos fluxos institucionais entre organizações formais.

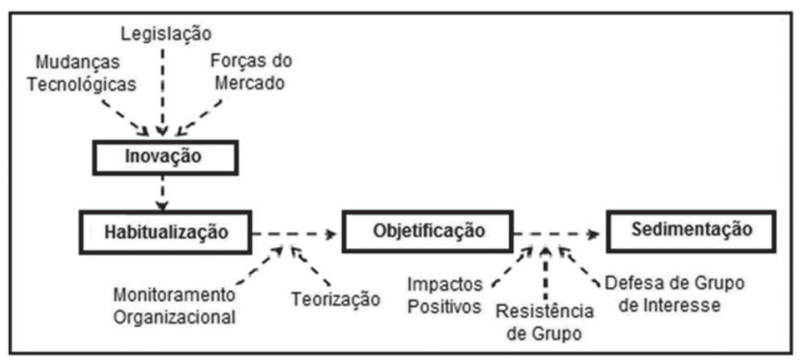

Figura 1: Processos inerentes à institucionalização Fonte: Tolbert e Zucker (2006, p. 205)

Analisando o processo de institucionalização, as referidas autoras consideram a existência de três processos: habitualização, objetificação e sedimentação, os quais podem ter níveis variados de institucionalização, dado que alguns padrões de comportamento social estão mais sujeitos do que outros à avaliação crítica, à modificação e mesmo à eliminação.

No processo de habitualização, de acordo com Tolbert e Zucker (2006), ocorre o desenvolvimento de novos arranjos estruturais em resposta a problemas ou a um conjunto de problemas organizacionais num determinado campo organizacional. Ocorre também a formalização de tais arranjos em políticas e procedimentos.

O resultado do processo de habitualização, conforme Tolbert e Zucker (2006), é o desenvolvimento de estruturas que podem ser classificadas como um estágio de Pré-institucionalização.

Os principais fatores que conduzem as organizações à inovação, ou à necessidade de inovar, são: mudanças tecnológicas, ou seja, reorientação técnica ou tecnológica; legislação, representando novos arranjos jurídicos que podem provocar maior ou menor receptividade por parte das organizações; $e$ forças do mercado, decorrentes de fatores econômicos. Portanto, 
são esses três fatores que conduzem a empresa à inovação e consequente processo de habitualização.

No processo de objetificação há certo grau de consenso social entre os decisores organizacionais em relação ao valor dos arranjos, procedimentos e modelos de estrutura, já disseminados e de caráter mais permanente (TOLBERT; ZUCKER, 2006). O desenvolvimento do consenso social entre os decisores da organização em relação ao valor do arranjo emerge de dois mecanismos diferentes, porém relacionados, a saber:

a) Pelo monitoramento interorganizacional, a partir da obtenção e análise de informações sobre sua disseminação em outras organizações do mesmo campo, implicando a difusão da estrutura.

b) Pela teorização, em que ocorre a definição clara dos problemas genéricos a serem corrigidos e a justificação de um novo arranjo estrutural formal, pela exposição de solução para o problema, com bases lógicas e testadas; esse mecanismo ocorre por meio do que é denominado champions (líderes).

Cabe ressaltar o papel dos champions nesse processo, pois eles representam os atores sociais que são as referências em segmentos ou favorecem a disseminação das práticas e, geralmente, empreendem esforços de teorização que legitimam a adoção da prática, uma vez que têm interesse material na sua definição. Os champions são agentes estimuladores, geralmente externos ou, quando dotados de poder, internos à organização; os mantenedores e os guardiões são os agentes internos, que desempenham o papel de retornar aos costumes tradicionais e continuar com o que já existe (mantenedor) e armazenar crenças e conceitos de mudança para colocá-los em prática oportunamente (guardião). No argumento de Dorado (2005), atores estratégicos podem alavancar apoio e aceitação e liderar a mudança institucional.

Ao final desse processo, a estrutura adquire legitimidade cognitiva e normativa. A legitimidade leva ao sucesso organizacional, e este, por sua vez, confere uma "legitimidade reversa" sobre certas instituições (RIAZ, 2009). Esse estágio é denominado por Tolbert e Zucker (2006, p. 207) de Semi-institucionalização.
As autoras alegam também que no estágio da Semi-institucionalização as estruturas, geralmente, têm taxa de sobrevivência mais longa comparada àquelas no estágio Pré-institucional, no entanto, nem todas perduram indefinidamente, pois, normalmente, têm história relativamente curta. Assim, as organizações continuarão a monitoração da acumulação de evidência, de sua própria organização e de outras, a respeito da eficácia das estruturas.

Já no processo de sedimentação ocorre a representação da continuidade da estrutura por um período de tempo relativamente longo, caracterizado por um momento em que a norma está totalmente sedimentada e, portanto, institucionalizada na organização. Corresponde ao estágio denominado Total Institucionalização.

O processo de sedimentação envolve duas dimensões: 1) a propagação, virtualmente completa, de suas estruturas por todo o grupo de atores teorizados como adotantes adequados; $e$ 2) a perpetuação de estruturas por um período consideravelmente longo de tempo. Nesse processo, que leva ao estágio da institucionalização total, atuam três variáveis principais: 1) impactos positivos de resultados; 2) baixa resistência de grupos de oposição; e 3) promoção e apoio continuado de grupos de defensores.

Nesse processo, as práticas, já aceitas amplamente, são vivenciadas como possuindo uma realidade própria e transmitidas como "dados sociais" para aqueles que não têm conhecimento de suas origens.

Portanto, o processo de institucionalização proposto por Tolbert e Zucker (2006) apresenta um conjunto de fatores que podem determinar se uma mudança organizacional, uma ação, um arranjo organizacional ou uma norma será ou não bem-sucedida $e$, à medida que avançam pelos estágios, apresentam taxa de sobrevivência crescente e mais longa.

Para Burns e Scapens (2000), regras e rotinas se tornam instituições quando são tidas como certas, são plenamente aceitas (taken for granted), e resistentes a alterações na organização.

Ao recorrer à Teoria Institucional como base teórica para este estudo, torna-se possível verificar o empenho da universidade em aprimorar suas capacidades gerenciais em favor da incorporação efetiva do modelo orçamentário em seus hábitos e rotinas. 


\section{Procedimentos Metodológicos}

Esta pesquisa caracteriza-se como descritiva e utiliza técnicas padronizadas de coleta de dados, sendo classificada como bibliográfica, documental $e$ de levantamento.

Adota a abordagem quantitativa, que, conforme Richardson et al. (1999), ocorre quando há o emprego da quantificação tanto nas modalidades de coleta de informações, quanto no tratamento delas por meio de técnicas estatísticas.

As 59 universidades federais constituem as unidades de análise desta pesquisa, cujo objeto de estudo é a institucionalização do Modelo Orçamentário, tendo como sujeitos da pesquisa os dirigentes da área de planejamento orçamentário.

Para desenvolvimento da pesquisa, utilizou-se de dados secundários e dados primários. Os dados secundários foram extraídos do documento intitulado "A Coleta de dados das IFES para Alocação de Recursos Orçamentários" da Sesu/MEC, da: Portaria n. 1.285/1994/MEC e do Decreto n. 7.233/2010.

Quanto aos dados primários, foram obtidos a partir de survey feito por aplicação de questionário aos dirigentes da área de orçamento das 59 universidades federais, sob a forma de autopreenchimento, composto de 21 afirmativas relacionadas à identificação do estágio de institucionalização do modelo, em que o respondente manifestou seu grau de concordância numa Escala Likert no formato de sete níveis de respostas.

Os dados coletados foram analisados por meio do Statistical Package for the Social Sciences (SPSS), versão 15.0, software estatístico para as ciências sociais, a partir da utilização das técnicas estatísticas de Análise de Cluster e Análise Discriminante.

Para cada estágio de institucionalização, na perspectiva de Tolbert e Zucker (2006), quais sejam: pré-institucionalização, Semi-institucionalização $e$ total institucionalização, está associado um conjunto de variáveis cujos escores foram somados, apurando-se a média dos escores da escala somada de cada uma das variáveis que compõem as dimensões (os estágios da institucionalização) e o construto maior de institucionalização do modelo de alocação de recursos orçamentários nas universidades federais.

Com a aplicação da Análise de Cluster, buscou-se agrupar as universidades federais de mesmo padrão de respostas em relação à percepção de seus dirigentes da área de orçamento sobre as variáveis que caracterizam os estágios de institucionalização.

A Análise de Cluster, também denominada Análise de Agrupamentos ou de Conglomerados, conforme Mingoti (2005), objetiva dividir os elementos da amostra ou população em grupos, de modo que os elementos pertencentes a um mesmo grupo sejam similares entre si e heterogêneos entre os grupos, nas mesmas variáveis.

Após a classificação dos grupos segundo os estágios de institucionalização do modelo, julgou-se procedente identificar as variáveis que mais diferenciam ou discriminam os grupos formados.

Assim, aplicou-se a técnica da Análise Discriminante, que é uma técnica estatística multivariada aplicada quando a variável dependente é qualitativa (grupos) e as variáveis independentes são quantitativas e visa escolher as variáveis que distinguem os grupos, de modo que, conhecendo as características de um novo caso, se possa prever a que grupo pertence. (PESTANA; GAGEIRO, 2008, p. 613)

De acordo com Maroco (2007, p. 513), a Análise Discriminante tem por objetivos: 1) identificar as variáveis que melhor diferenciam (ou "discriminam") entre dois ou mais grupos de indivíduos estruturalmente diferentes e mutuamente exclusivos; 2) utilizar estas variáveis para criar um "índice" ou "função discriminante" que represente de forma parcimoniosa as diferenças entre os grupos; e 3) utilizar esta função discriminante para classificar a priori novos indivíduos nos grupos.

\section{Resultados e Discussões}

A pesquisa contou com a participação de $67,8 \%$, ou seja, de 40 respondentes dos questionários enviados aos dirigentes da área de planejamento e orçamento das 59 universidades federais.

Inicialmente, buscou-se identificar, por meio da análise multivariada, a formação de Clusters das universidades segundo os estágios de institucionalização em que se encontram, na perspectiva de Tolbert e Zucker (2006), quais sejam pré-institucionalização, Semi-institucionalização e total institucionalização.

Para tanto, a partir das 21 questões do questionário, foram definidas as variáveis que foram submetidas 
à análise estatística para identificação da percepção dos sujeitos da pesquisa sobre a institucionalização do modelo de alocação de recursos orçamentários das universidades.

Para caracterizar o construto do Estágio da Pré-institucionalização, foram alocadas as variáveis: inovação, diretrizes governamentais, instâncias governamentais, controle e auditoria de desempenho, valorização da sociedade, visibilidade da universidade e melhores práticas. Buscou-se, assim, identificar a percepção dos sujeitos da pesquisa em relação à adoção do modelo orçamentário como forma de atender às diretrizes governamentais e às demandas da sociedade e como contrapartida à qualidade do desempenho da universidade.

Para o constructo do Estágio da Semi-institucionalização, as variáveis foram: compartilhamento de ideias e práticas, acompanhamento de universidades de referência, divulgação e participação, agentes facilitadores e estimuladores, valorização da comunidade universitária, conhecimento de dirigentes estratégicos e implicações das decisões estratégicas.

Ressalta-se que neste estágio, as questões formuladas visavam identificar se o modelo orçamentário tem significado e valor na organização, diante da consciência de determinado problema organizacional e de que o mesmo é passível de solução por meio de uma estrutura específica. Visava-se, também, verificar o empenho da universidade em alcançar melhor posicionamento no modelo orçamentário, propiciando a divulgação e envolvimento dos dirigentes e da comunidade acadêmica nas decisões estratégicas relacionadas às variáveis.

Por fim, para o constructo do Estágio da Total Institucionalização, foram alocadas as variáveis: reflexo positivo da gestão, apoio logístico, equipe técnica qualificada, indutor de eficiência, apoio geral da comunidade universitária, acompanhamento sistemático e estabelecimento de ações compatíveis. Com estas variáveis objetivou-se identificar em que medida o modelo orçamentário tem se tornado uma ação habitual para as universidades federais, caracterizando-se pela continuidade histórica da estrutura e sua sobrevivência pelas várias gerações de membros da organização. Além disto, buscou-se apurar o quão a universidade percebe os aspectos positivo da adoção do modelo orçamentário e, portanto, se estrutura com apoio logístico e equipe qualificada para seu acompanhamento sistemático.
Antes de proceder à formação dos clusters realizou-se o teste de confiabilidade do constructo da institucionalização em seus três estágios, por meio do Alfa de Conbrach das variáveis, verificando-se que para cada estágio ele é superior a 0,8 (Tabela 1), considerado "Muito Bom", o que determina que o construto reflete com confiabilidade o fenômeno investigado, pois suas variáveis são fortemente correlacionadas.

\subsection{Análise de Cluster}

Para a fase referente à formação de Clusters, inicialmente, procedeu-se à redução das variáveis, por meio da escala somada de seus escores médios conforme composição de cada um dos três estágios da institucionalização: pré-institucionalização, Semi-institucionalização e total institucionalização. O uso da Escala Somada é recomendado por Hair Jr. . (2005) quando o Alfa de Cronbach for superior a 0,7, requisito cumprido nesta pesquisa (Tabela 1).

Com a aplicação da técnica, considerou-se mais adequado a retenção de dois grupamentos de universidades, já que estes possibilitariam uma melhor interpretação dos dados, tendo em vista o suporte teórico adotado.

Ao Cluster 1, composto por 29 universidades $(72,5 \%)$ convencionou-se chamar "Melhor nível de institucionalização" e Cluster 2, composto por 11 universidades (27,5\%), "Pior nível de institucionalização", tendo em vista que o Cluster 1 tem os escores médios mais altos que o Cluster 2 em todos os estágios da institucionalização, conforme Tabela 2.

O melhor nível de institucionalização é aqui entendido como a maior capacidade da universidade em agir conforme o que se espera de cada estágio, o que se verificou na percepção de $72,5 \%$ dos sujeitos da pesquisa, embora apresente obstáculos em algumas variáveis características de cada estágio da institucionalização do modelo orçamentário.

Para 27,5\% das universidades, Cluster 2, na percepção dos sujeitos da pesquisa, o modelo orçamentário apresenta-se em nível ruim a regular de institucionalização com indicativos de necessidade de melhoria na gestão em todas as variáveis dos três estágios da institucionalização, por não corresponder ao que se espera de cada estágio. 
Tabela 1: Alfa de Cronbach para grupos de variáveis segundo os estágios da institucionalização visando à definição de Clusters

\begin{tabular}{llll}
\hline Estágio & No & \multicolumn{1}{c}{ Variáveis } & $\begin{array}{c}\text { Alpha de } \\
\text { Cronbach }\end{array}$ \\
\hline & 1 & $>$ Inovação na gestão & \\
& 2 & $>$ Diretrizes governamentais & 0,836 \\
E stágio 1 & 4 & $>$ Instâncias governamentais & \\
& 5 & $>$ Controle e auditoria de desempenho & \\
& 6 & $>$ Valorização da sociedade & \\
& 7 & $>$ Visibilidade da universidade & \\
& 8 & $>$ Compres práticas & \\
9 & $>$ Acompanhamento das universidades de referência & \\
& 10 & $>$ Divulgação e participação & \\
11 & $>$ Agentes facilitadores e estimuladores (Champions) & \\
12 & $>$ Valorização da comunidade universitária & \\
13 & $>$ Conhecimento dos dirigentes estratégicos & \\
14 & $>$ Implicações das decisões estratégicas & \\
& 15 & $>$ Reflexo positivo da gestão & \\
16 & $>$ Apoio logístico & \\
17 & $>$ Equipe técnica qualificada & \\
18 & $>$ Indutor da eficiência & \\
19 & $>$ Apoio geral da comunidade universitária & \\
20 & $>$ Acompanhamento sistemático & \\
21 & $>$ Estabelecimento de ações compatíveis & \\
\hline & & &
\end{tabular}

Fonte: Dados da pesquisa

Tabela 2: Formação dos clusters por estágio de institucionalização

\begin{tabular}{cllllll}
\hline \multirow{2}{*}{ Cluster } & \multicolumn{1}{c}{ Estágio } & No & Mínimo & Máximo & Média & $\begin{array}{c}\text { Desvio } \\
\text { padrão }\end{array}$ \\
& Estágio 1 - Pré insttucionalização & 29 & 4,00 & 6,43 & 5,3202 & 0,5118 \\
\multirow{2}{*}{1} & Estágio 2 - Semi institucionalização & 29 & 4,00 & 6,71 & 5,5714 & 0,6061 \\
& Estágio 3 - Total institucionalização & 29 & 4,00 & 6,86 & 5,4138 & 0,7023 \\
\hline \multirow{2}{*}{2} & Estágio 1 - Pré insttucionalização & 11 & 1,86 & 5,86 & 4,2987 & 1,4307 \\
& Estágio 2 - Semi institucionalização & 11 & 2,86 & 4,86 & 3,8961 & 0,7589 \\
& Estágio 3 - Total institucionalização & 11 & 1,57 & 4,29 & 3,2857 & 0,8452 \\
\hline
\end{tabular}

Nota: Para classificação dos resultados da média foram usados os intervalos: 1 a 1,5 péssimo; 1,6 a 2,5, muito ruim; 2,6 a 3,5 ruim; 3,6 a 4,5 regular; 4,6 a 5,5 bom; 5,6 a 6,5 muito bom; e 6,6 a 7 ótimo.

Fonte: Dados da pesquisa 
Baseado nas argumentações de Tolbert e Zucker (2006) e Jepperson (1991), um determinado instrumento, norma ou procedimento, pode apresentar variados graus de institucionalização, decorrentes do tempo de instituição, da incorporação a um campo organizacional ou do questionamento que o ambiente social faz sobre ele.

De acordo com Tolbert e Zucker (2006), a institucionalização aparece tanto como processo quanto como variável tributo. Neste último caso, a institucionalização é quase sempre tratada como um estado qualitativo: ou as estruturas são institucionalizadas ou não o são. No entanto, vista como um processo, é possivel analisar os fatores determinantes das variações nos níveis de institucionalização, e sobre como essas variações podem afetar o grau de similaridade entre os conjuntos de organizações.

Assim, ao tratar a institucionalização como um processo, realizou-se a Análise Discriminante, para determinar as variáveis que distinguem significativamente os grupos formados.

\subsection{Análise Discriminante}

Para se proceder à Análise Discriminante foram tratadas como variáveis dependentes não métricas o nível de institucionalização do modelo orçamentário estabelecido em função da formação dos dois grupos de clusters em "Melhor nível de institucionalização" e "Pior nível de institucionalização", e, como independentes as variáveis métricas utilizadas para avaliar os estágios da institucionalização.

Inicialmente, buscou-se verificar a existência de condições adequadas para o emprego da técnica de Análise Discriminante, quais sejam: distribuição normal multivariada, igualdade das matrizes de covariância e inexistência de multicolinearidade.

Para verificação da normalidade das variáveis utilizou-se o teste de Kolmogorov-Smirnov, chamado teste K-S, cujos resultados por estágio de institucionalização são apresentados na Tabela 3. Os estágios da institucionalização representam a escala somada dos escores médios das variáveis utilizadas na formação dos clusters.

Tabela 3: Teste K-S de normalidade das variáveis

\begin{tabular}{cccccccc}
\hline & Cluster & Kolmogorov-Smirnov & df & Sig. & Shapiro-Wilk & df & Sig. \\
\hline Estágio 1 - Pré & 1 & 0,0827 & 29 & 0,200 & 0,9840 & 29 & 0,926 \\
institucionalização & 2 & 0,1768 & 11 & 0,200 & 0,8973 & 11 & 0,171 \\
Estágio 2 - Semi & 1 & 0,1118 & 29 & 0,200 & 0,9737 & 29 & 0,663 \\
institucionalização & 2 & 0,2416 & 11 & 0,072 & 0,8708 & 11 & 0,079 \\
Estágio 3 - Total & 1 & 0,1636 & 29 & 0,046 & 0,9314 & 29 & 0,060 \\
institucionalização & 2 & 0,1602 & 11 & 0,200 & 0,9325 & 11 & 0,437 \\
\hline
\end{tabular}

Fonte: Dados da pesquisa

O teste K-S testa a hipótese nula da normalidade da população contra a hipótese alternativa da não normalidade. Assim, verifica-se que, em nível de significância de 5\%, rejeita-se a hipótese de normalidade no Estágio 3 - Total institucionalização para o Cluster 1 , que está ligeiramente afastado da normalidade, o que não inviabiliza que se prossiga com a análise discriminante. (PESTANA; GAGEIRO, 2008)

O teste Shapiro-Wilk, constante da Tabela 3, é outra medida para avaliar o tipo de distribuição das observações, sendo mais indicado quando o número de amostras é de pequena dimensão (menos de 30 observações). De acordo com seus resultados, não se pode negar a normalidade da população, em nível de significância de 5\%.

O outro pressuposto básico da análise discriminante é a igualdade das matrizes de covariância, testada pelo $M$ de Box. Os resultados (Quadro 1) mostram-se favoráveis à aplicação da técnica, uma vez que, com o p-value de 0,195 não se pode rejeitar a hipótese $\left(H_{0}\right)$ da igualdade das matrizes de variância-covariância para os dois grupos de clusters. Ou seja, pode-se concluir pela igualdade das dispersões entre os clusters, qualquer que seja o erro tipo I do analista (PESTANA; GAGEIRO, 2008). 


\begin{tabular}{|llr|}
\hline Box's M & & 16,203 \\
F & Approx. & 1,357 \\
& df1 & 10,000 \\
& df2 & $1.675,670$ \\
& Sig. & 0,195 \\
\hline
\end{tabular}

Quadro 1: Teste de M de Box

Fonte: Dados da pesquisa

Por fim, verificou-se, também, que não há problemas de multicolinearidade, uma vez que os coeficientes de correlação entre as variáveis independentes são inferiores em termos absolutos a 0,9 (PESTANA; GAGEIRO, 2008). A mais alta correlação é de 0,6849 , entre as variáveis "Visibilidade da universidade" e "Indutor de eficiência".

O processo de estimação da função discriminante se inicia com a identificação das variáveis que discriminam os grupos de universidades que foram classificados como as de "Melhor nível de institucionalização" e as de "Pior nível de institucionalização".

Assim, inicialmente, é gerada a matriz de estrutura (Tabela 4) que evidencia a contribuição de cada variável para cada função discriminante. Quanto maiores foram os coeficientes (em valor absoluto), mais a função discriminante detém a informação contida nessas variáveis.

Nesta pesquisa, com a opção pela retenção de dois clusters, foi gerada apenas uma função, pois o número de função é sempre igual ao número de clusters menos 1 .

Para escolher entre todas as variáveis aquelas que deverão compor o modelo discriminatório, fez-se uso do método Stepwise. Com esse método, a partir da escolha da melhor variável discriminatória, no caso, a variável "Estabelecimento de ações compatíveis", pois é a de maior coeficiente (Tabela 4), faz-se o par com cada uma das outras variáveis independentes, uma de cada vez, e as variáveis que não são úteis na discriminação entre os grupos são eliminadas e um conjunto reduzido de variáveis é identificado, que por vezes, é quase tão bom, ou melhor, que o conjunto completo de variáveis. (HAIR JR., 2009)

No método Stepwise, uma variável presente na função discriminante é removida se isso não provocar redução Tabela 5: Teste de igualdade de médias na capacidade da função discriminante, e também uma variável é adicionada se aumentar significativamente sua capacidade discriminativa. (MAROCO, 2007)

Tabela 4: Contribuição de cada variável para a função discriminante

\begin{tabular}{lc}
\hline \multicolumn{1}{c}{ Variável } & Função 1 \\
\hline Estabelecimento de ações compatíveis & 0,7353 \\
Implicações das decis ões estratégicas & 0,6281 \\
Acompanhamento das universidades de referência & 0,5192 \\
Divulgação e participação & 0,4956 \\
Indutor de eficiência & 0,4836 \\
Acompanhamento sistemático & 0,4709 \\
Compartilhamento de ideias e práticas & 0,4468 \\
Apoio geral da comunidade universitária & 0,4386 \\
Instâncias governamentais & 0,3952 \\
Agentes facilitadores e estimuladores & 0,3920 \\
Melhores práticas & 0,3723 \\
Equipe técnica qualificada & 0,3554 \\
Reflexo pos itivo da gestão & 0,2627 \\
Diretrizes governamentais & 0,2591 \\
Apoio logístico & 0,2223 \\
Conhecimento dos dirigentes estratégicos & 0,2124 \\
Valorização da sociedade & 0,1805 \\
Visibilidade da universidade & 0,1801 \\
Controle e auditoria de desempenho & 0,1324 \\
Inovação na gestão & $(0,0888)$ \\
Valorização da comunidade universitária & $(0,0564)$ \\
\hline Fonte: Dados da pesquisa & \\
\hline
\end{tabular}

Fonte: Dados da pesquisa

Da aplicação desse método observam-se no Tabela 5 as variáveis mais úteis na discriminação entre os grupos. Em nível de significância de 5\%, nota-se que o valor $F$ é alto em todas as variáveis, o que indica serem essas variáveis significativas para descrever os grupos mais parecidos e testar a igualdade das médias (centroides) dos grupos, possibilitando grande distância entre cada par de grupos.

A Tabela 5 também mostra a significância da função discriminante ao apresentar baixos valores para o lambda $(\lambda)$ de Wilks, que variam entre 0 e 1 . Os baixos valores indicam grandes diferenças entre os grupos, enquanto os valores elevados indicariam não haver diferenças nesses grupos.

\begin{tabular}{clccc}
\hline Step & \multicolumn{1}{c}{ Variável } & Wilks' Lambda & F & Sig. \\
\hline 1 & Estabelecimento de ações compatíveis & 0,348 & 71,071 & 0,000 \\
2 & Instâncias governamentais & 0,295 & 44,191 & 0,000 \\
3 & Compartilhamento de ideias e práticas & 0,251 & 35,894 & 0,000 \\
4 & Controle e auditoria de desempenho & 0,224 & 30,267 & 0,000 \\
\hline
\end{tabular}

Fonte: Dados da pesquisa 
Assim, as variáveis "Estabelecimento de ações compatíveis", "Instâncias governamentais", "Compartilhamento de ideias e práticas" e "Controle e auditoria de desempenho" são significantes na função discriminatória.

Para construção da função discriminante, é necessário avaliar a representatividade de seus escores. A Tabela 6 indica que, com o valor eigenvalue de 3,459, a função discriminante 1 explica $100 \%$ da variância em termos de diferenças entre os grupos com as variáveis selecionadas.

Tabela 6: Significância da função discriminante

\begin{tabular}{cccc}
\hline Função & Eigenvalue & $\%$ de variância & Cor relação canônica \\
\hline 1 & 3,459 & 100,00 & 0,881 \\
\hline
\end{tabular}

Fonte: Dados da pesquisa

Vale ressaltar que os valores próprios (eigenvalue) correspondem à relação que se obtém da divisão que resulta da variação entre os grupos pela variação dentro dos grupos. Quanto mais afastados de 1, maior será a variação entre os grupos explicada pela função discriminante.

Apresentando uma correlação canônica da função discriminante de 0,881 , tem-se que $77,6 \%$ (ou seja, $0,8812 \times 100)$ da variância da variável dependente pode ser explicada por esse modelo de quatro variáveis independentes.

A técnica da Análise Discriminante, então, gera a equação linear com os coeficientes das variáveis selecionadas e um fator constante, conforme Tabela 7.

Tabela 7: Coeficientes da função discriminante canônica

\begin{tabular}{lc}
\hline \multicolumn{1}{c}{ V ariável } & Função 1 \\
\hline Controle e auditoria de desempenho & $-0,279$ \\
Instâncias governamentais & 0,666 \\
Compartilhamento de ideias e praticas & 0,566 \\
Estabelecimento de ações compatíveis & 0,737 \\
(Constante) & $\mathbf{- 8 , 2 3 1}$ \\
\hline
\end{tabular}

Fonte: Dados da pesquisa

A equação da função discriminante é assim representada:

$Z_{(1)}=-8,231-(0,279 \mathrm{X}$ Controle e auditoria de desempenho $)+(0,666 \mathrm{X}$ Instâncias governamentais $)+$ (0,566 X Compartilhamento de ideias e práticas $)+(0,737$ X Estabelecimento de ações compatíveis $)$

Os coeficientes, além de fornecerem o modelo da função discriminante, informam, em ordem de grandeza, as correlações simples entre as variáveis preditoras e a função discriminante. (HAIR JR., 2009)

O que equivale a dizer que as variáveis "Instâncias governamentais", "Compartilhamento de ideias e práticas" e "Estabelecimento de ações compatíveis" são as que mais contribuem, de forma positiva, para discriminar o nível de institucionalização do modelo orçamentário nas universidades federais. A variável
"Estabelecimento de ações compatíveis" é a que mais contribui, pois tem o maior coeficiente $(0,737)$.

Uma vez estimada a função discriminante, outra etapa consiste em aferir a classificação dos sujeitos no modelo, por meio dos coeficientes não padronizados para o procedimento de classificação. A função gerada serve apenas para a classificação e não tem qualquer interpretação discriminativa, sendo também conhecida como função discriminante linear de Fischer, conforme apresentado na Tabela 8.

Tabela 8: Coeficientes da função discriminante de Fisher

\begin{tabular}{lcc}
\hline \multicolumn{1}{c}{ Var iável } & Cluster 1 & Cluster 2 \\
\hline Controle e auditoria de desempenho & $-1,781$ & $-0,647$ \\
Instâncias governamentais & 7,051 & 4,347 \\
Compartilhamento de ideias e praticas & 5,928 & 3,628 \\
Estabelecimento de ações compatíveis & 5,660 & 2,667 \\
(Constant) & $-46,977$ & $-17,268$ \\
\hline
\end{tabular}

Fonte: Dados da pesquisa 
A equação para cada um dos clusters seria assim representada:

$Z_{(1)}=-46,977$ - (1,781 X Controle e auditoria de desempenho) + (7,051 X Instâncias governamentais $)+$ (5,928 X Compartilhamento de ideias e práticas) + (5,660 X Estabelecimento de ações compatíveis)

$Z_{(2)}=-17,268$ - (0,647 X Controle e auditoria de desempenho) + (4,347 X Instâncias governamentais $)+$ (3,628 X Compartilhamento de ideias e práticas) $+(2,667 \mathrm{X}$ Estabelecimento de ações compatíveis)

Para estimar a que cluster pertenceria a uma universidade que pontuasse, por exemplo, a variável "Controle e auditoria de desempenho" em 4, "Instâncias governamentais" em 5, "Compartilhamento de ideias e práticas" em 3 e "Estabelecimento de ações compatíveis" em 4, seu score em cada uma das funções de classificação seria:

para o Cluster 1:

Função $_{(1)}=-46,977-(1,781$ X 4) + (7,051 X 5) + (5,928 X 3) $+(5,660 \times 4)=20,538$

e para o Cluster 2:

Função $_{(2)}=-17,268-(0,647$ X 4) $+(4,347$ X 5) $+(3,628$ X 3) $+(2,667$ X 4) $=2,095$

Esta universidade seria, então, classificada no Cluster 1 , já que neste grupo se observa o maior valor das funções de classificação.

A aplicação da técnica da Análise Discriminante possibilitou cumprir o objetivo de identificar as variáveis que mais diferenciam as universidades do Cluster 1 daquelas do Cluster 2, quanto ao nível de institucionalização do modelo orçamentário.

\section{Síntese e Conclusões}

Com o objetivo de agrupar as universidades federais conforme o estágio de institucionalização em que se encontram em relação ao modelo de alocação de recursos orçamentários de OCC, identificando as variáveis que mais discriminam os grupos formados, foram sujeitos estratégicos da pesquisa os dirigentes da área de planejamento orçamentário das 59 universidades federais aos quais se aplicou questionário de autopreenchimento.

Inicialmente, buscou-se identificar o nível de institucionalização do modelo orçamentário nas universidades federais, conforme definições das autoras
Tolbert e Zucker (2006) que consideram, no processo de institucionalização, a existência de três estágios denominados: Pré-institucionalização, Semi-institucionalização e Total institucionalização.

Para a maioria dos respondentes da pesquisa (72,5\%), o modelo orçamentário em sua universidade se encontra em melhores níveis de institucionalização quando comparado aos demais (27,5\%). O melhor nível de institucionalização é aqui entendido como a maior capacidade da universidade em agir conforme o que se espera de cada estágio.

Posteriormente, no intuito de identificar as variáveis que mais diferenciam o grupo de universidades com "Melhor nível de institucionalização" (Cluster 1) do grupo de "Pior nível de institucionalização" (Cluster 2), aplicou-se a Técnica de Análise Discriminante.

Constatou-se então, que as variáveis "Controle e auditoria de desempenho", "Instâncias governamentais", "Compartilhamento de ideias e práticas", e "Estabelecimento de ações compatíveis" são as que mais diferenciam um grupo do outro.

Observa-se que as variáveis "Controle e auditoria de desempenho" e "Instâncias governamentais" constituem características do estágio Pré-Institucional 
e apontam a aceitação das universidades quanto à influência dos stakeholders na gestão universitária.

Já a variável "Compartilhamento de ideias e práticas" é fundamental na identificação da disposição das universidades em compartilhar conhecimento e ideias em relação a melhorias no modelo, possibilitando-o estar em melhor nível no estágio Semi-institucional. Neste estágio, os significados atribuídos à ação habitual se tornaram generalizados, levando ao monitoramento do que outras universidades fazem com vistas ao aumento da competividade relativa.

Por fim, a variável "Estabelecimento de ações compatíveis" retrata a capacidade da universidade em fazer gestão do modelo de forma que suas ações estratégicas sejam compatíveis com seus princípios filosóficos, habilitando-a para a total institucionalização. Nesse estágio, a correlação positiva com resultados desejados é um dos fatores que podem assegurar a perpetuação do modelo.

As variáveis apontadas indicam que o gestor universitário deve consolidar práticas, regras e valores que influenciem suas decisões e ações, principalmente nas universidades que compõem o Cluster 2.

É importante que os gestores universitários reconheçam no modelo orçamentário uma ferramenta que induza ao cumprimento das metas governamentais com vistas à expansão e melhoria da qualidade da educação superior, refletidas no desempenho da universidade. É preciso proporcionar, entre as universidadese nos fóruns próprios, o compartilhamento de ideias e práticas necessárias ao aperfeiçoamento do modelo. Sobretudo, é fundamental que se faça a gestão das variáveis, estabelecendo ações articuladas e compatíveis com o princípio conceitual do modelo orçamentário, na medida em que não permita a ocorrência de vagas ociosas, aproveitando ao máximo a capacidade instalada da universidade; implemente medidas para diminuir a retenção e evasão de alunos; amplie o número de vagas nos programas de pós-graduação e proporcione condições de melhoria nas variáveis de avaliação da Capes; aumente o número de cursos ou de vagas em cursos noturnos e fora de sede; avalie as implicações da mudança de curso noturno para diurno; e outros.

Entendendo ser o modelo orçamentário das universidades federais ferramenta que pode contribuir para a gestão universitária de qualidade, cabe aos gestores públicos torná-lo parte de seus hábitos e rotinas, tentando sanar os obstáculos à sua total institucionalização e, assim, alcançar o melhor desempenho nas variáveis que o compõem.

Em cerca de $30 \%$ das universidades pesquisadas, a institucionalização do modelo orçamentário está mais comprometida, podendo indicar que não tem sido possível adotar uma administração gerencial em relação a ele. Tendo em vista que a valorização e continuidade de um procedimento na organização requerem liderança e equipe qualificada, nestas universidades estas condições não têm sido atendidas, podendo ser reflexo do predomínio das características próprias da gestão pública universitária, marcada pelo fator político e pelas frequentes mudanças de atores estratégicos.

Esta pesquisa apresenta como limitação o possível fato de outras variáveis relacionadas ao modelo da alocação de recursos orçamentários poderem ser definidas para a caracterização dos estágios de institucionalização, levando a resultados diferentes dos obtidos.

\section{REFERÊNCIAS}

ABRUCIO, F. L. Trajetória recente da gestão pública brasileira: um balanço crítico e a renovação da agenda de reformas. Revista de Administração Pública, Rio de Janeiro, edição comemorativa, v. 1, p. 67-74, 2007.

AMARAL, Nelson Cardoso. A Vinculação avaliação/ financiamento na educação superior brasileira. Impulso, Piracicaba, v. 16, n. 40, p. 81-91, 2005.

Financiamento da educação superior: estado x mercado. São Paulo: Cortez; Piracicaba, SP: UNIMEP, 2003.

\section{BERGER, P. L.; LUCKMANN, T. A Construção social da}

realidade. Petrópolis: Vozes, 1985.

BRASIL. Decreto n. 7.233, de 19 de julho de 2010.

Dispõe sobre procedimentos orçamentários e financeiros relacionados à autonomia universitária, e dá outras providências. Diário Oficial da União - DOU, Brasília, DF, 20 de julho de 2010.

Ministério da Educação. Secretaria de Educação

Superior. A coleta de dados das IFES para alocação

de recursos orçamentários. Brasília, DF, nov. 2006. 
Lei n. 10.172, de 9 de janeiro de 2001. Plano Nacional de Educação. Brasília: DF, 2001.

BRESSER-PEREIRA, L. C. Da administração pública burocrática à gerencial. In: BRESSER-PEREIRA, Luiz Carlos; SPINK, Peter Kevin. (Org.). Reforma do estado e administração pública gerencial. 7. ed. Rio de Janeiro: Editora FGV, 2006. 316 p.

BRESSER-PEREIRA, L. C. Reforma gerencial do Estado, teoria política e ensino da administração pública. Revista Gestão e Políticas Públicas/RGPP, São Paulo, v. 1, n. 2, p. 1-6, 2011.

BURNS, J.; SCAPENS, R. W. Conceptualizing management accounting change: an institutional framework. Management Accounting Research, Philadelphia, PA, USA, v. 11, p. 3-25, 2000.

CARVALHO, Cristina Amélia Pereira de; VIEIRA, M. M. F.; LOPES, F. D. Contribuições da perspectiva institucional para análise das organizações. In: XXIII ENANPAD ENCONTRO ANUAL DA ANPAD, Foz do Iguaçu. Anais Eletrônicos, 1999. Foz do Iguaçu, ANPAD, 1999.

CAVALCANTE, Pedro Luiz. Orçamento por desempenho: uma análise comparativa do modelo de avaliação dos programas governamentais no Brasil e nos Estados Unidos. In: II CONGRESSO CONSELHO NACIONAL DE SECRETÁRIOS DE ESTADO DA ADMINISTRAÇÃO (CONSAD) DE GESTÃO PÚBLICA - Painel 31: Qualidade do gasto público I. Anais... Brasília, DF, 2009. Brasília, DF, 2009.

CEPAL. Educação e conhecimento: eixo de transformação produtiva com equidade. Brasília, DF: IPEA/CEPAL/INEP, 1995.

DI MAGGIO, P. J.; POWELL, W. W. A gaiola de ferro revisitada: isomorfismo institucional e racionalidade coletiva nos campos organizacionais. Revista de Administração de Empresas - RAE, São Paulo, v. 45, n. 2, p. 74-89, 2005.

DORADO, S. Institutional entrepreneurship, partaking, and convening. Organization Studies, Stanford University, Stanford, USA, v. 26, n. 3, p. 385-414, 2005.
FONSECA, Valéria; MACHADO-DA-SILVA, Clóvis

L. Conversação entre Abordagens da Estratégia em Organizações: Escolha Estratégica, Cognição e Instituição. Revista de Administração Contemporânea-RAC, Curitiba, Edição Especial, p. 51-75, 2010.

FONSECA, Valéria Silva da. A abordagem institucional nos estudos organizacionais: bases conceituais $e$ desenvolvimentos contemporâneos. In: CARVALHO, Cristina Amélia; vieira, marcelo milano falcão. (org.).

organizações, cultura e Desenvolvimento Local: a agenda de pesquisa do Observatório da Realidade Organizacional. 1. ed. Recife: Editora Universitária UFPE, 2003, v. 1, p. 23-178

GUERREIRO, Reinaldo; FREZATTI, F; CASADO, T. Em busca do entendimento da formação dos hábitos, rotinas e instituições da contabilidade gerencial. In: $4^{\circ}$ CONGRESSO USP DE CONTROLADORIA E CONTABILIDADE. São Paulo: EAC/FEA/USP, 2004.

Anais... São Paulo, USP, 2004.

HAIR JR., Joseph F; BABIN, Barry; MONEY, Arthur H.; SAMUEL, Phillip. Fundamentos de métodos de pesquisa em administração. Porto Alegre: Bookman, 2005.

HAIR JR., J. F.; BLACK, W. C.; BABIN, B. J.; ANDERSON, R. E.; TATHAM, R. L. Análise multivariada de dados. 6. ed. Porto Alegre: Bookman, 2009.

JANNUZZI, Paulo de Martino. Indicadores para diagnóstico, monitoramento e avaliação de programas sociais no Brasil.

Revista do Serviço Público - RSP, Brasília, DF, v. 56, n. 2, p. 137-160, abr.-jun., 2005.

JEPPERSON, Ronald L. Institutions, institutional effects, and institutionalization. In: POWELL, Walter W.; DIMAGGIO, Paul J. (Ed.). The New Institutionalism in Organizational Analysis. Chicago: University of Chicago Press, 1991. p. 143-63.

LUSTOSA DA COSTA, F; CASTANHAR, J. C. Avaliação de programas públicos: desafios conceituais e metodológicos. Revista de Administração Pública - RAP, Rio de Janeiro, v. 37, n. 5, p. 969-92, set.-out., 2003. 
MAROCO, João. Análise estatística com utilização do SPSS. 3. ed. Lisboa: Edições Sílabo, 2007.

MEYER, J. W.; ROWAN, B. Institutionalized organizations: formal structure as myth and ceremony. The Americam Journal of Sociology, Chicago, IL, USA, v. 83, n. 2, p. 340-363, 1977.

MEYER Jr., V. Novo contexto e as habilidades do administrador universitário. In: MEYER Jr., V.; P.

MURPHY (Org.). Dinossauros, gazelas e tigres: novas abordagens da administração universitária. Florianópolis, Insular, 2000, p. 173-192.

MINGOTI, Sueli Aparecida. Análise de dados através de estatística multivariada: uma abordagem aplicada. Belo Horizonte: Editora UFMG, 2005. 297 p.

NOR-AZIAH, A. K.; SCAPENS, R. W. Corporatisation and accounting change: the role of accounting and accountants in a Malaysian public utility. Management Accounting Research. Philadelphia, PA, USA, v. 18, n. 2, p. 209-47, 2007.

PESTANA, Maria Helena; GAGEIRO, João Nunes.

Análise de dados para ciências sociais: a complementaridade do SPSS. 5. ed. Lisboa: Edições Silabo, 2008. 692 p.

PRATES, A. A. P. A Questão do gerenciamento das IFES no Cenário de Autonomia. In: DURHAM, R. E.; SAMPAIO, H. (Org.). O Ensino superior em transformação. São Paulo: NUPES/USP, 2001.

RIAZ, Suhaib. The global financial crisis: an institutional theory analysis. Critical Perspectives on International Business, Bingley, West Yorkshire, England, v. 5, n. 1/2, p. 26-35, 2009.

RICHARDSON, Robert Jarry et al. (Org.) Pesquisa social: métodos e técnicas. São Paulo: Atlas, 1999.

SUDDABY, Roy. Challenges for Institutional Theory.

Journal of Management Inquiry, Stanford University, Stanford, USA, v. 19, n. 1, p. 14-20, 2010.
SOUTES, Dione Olesczuk. Uma investigação do uso de artefatos da contabilidade gerencial por empresas brasileiras.116p. Dissertação (Mestrado em Controladoria e Contabilidade). Faculdade de Economia, Administração e Contabilidade da USP. São Paulo, 2006.

TOLBERT, Pamela S.; ZUCKER, Lynne G. A institucionalização da teoria institucional. In: CLEGG, Stewart R. et al. (Org.). Handbook de estudos organizacionais: modelos de análises e novas questões em estudos organizacionais. 3. reimpressão. São Paulo: Atlas, 2006,

ZUCKER, L. G. The role of institutionalization in cultural persistence. In: DiMAGGIO, P. J.; POWELL, W. W.

(Edit.). The new institutionalism in organizational analysis. Chicago: The University of Chicago Press, 1991. p. 83-107. 